\title{
¿Por qué publicar en RETLA?
}

\section{Why publish in RETLA?}

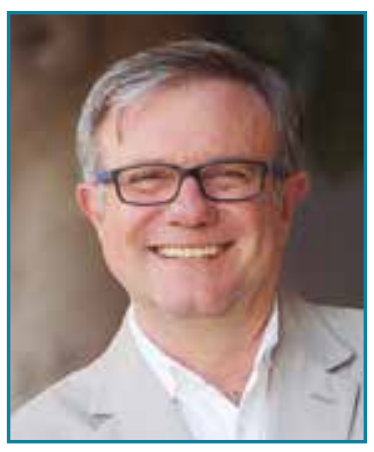

Eduardo Sánchez Alepuz Editor de RETLA
- a Revista Española de Traumatología Laboral (RETLA) nace con el objetivo - de vehiculizar a nivel científico las distintas profesiones que participan en el proceso sanitario de la patología laboral. A diferencia de las múltiples revistas médicas que pueblan el conocimiento sanitario, RETLA quiere ser integradora del manejo del paciente desde el médico asistencial que lo recibe en primera instancia hasta el especialista que lo trata al final de proceso; por este motivo, RETLA es el marco donde enfermería, fisioterapia, medicina asistencial y especializada, gestores del proceso sanitario y todo profesional vinculado con la patología laboral pueden y deben expresar el conocimiento de sus áreas de trabajo, permitiendo un conocimiento multidisciplinar del proceso completo de tratamiento de un paciente laboral.

¿Por qué publicar en RETLA? Para alcanzar los objetivos integradores interprofesionales dentro de un proceso terapéutico y poder establecer una interrelación científica entre los profesionales que conforman las diferentes mutuas laborales de nuestra red sanitaria, incrementando el enriquecimiento en la cultura sanitaria laboral.

Por todo lo anterior y dado que RETLA es muy joven, no tiene ni un año, como editor de la revista quiero invitaros a todos a publicar, a contar vuestras experiencias, conocimientos, formas de trabajo, innovaciones, descubrimientos... desde una perspectiva científica y ajustándose a una normativa editorial rigurosa que encontraréis en la página web de SETLA. Porque transmitir nuestros conocimientos enriquece no solo al que recibe esa información, sino que hace más grande profesionalmente al que de manera altruista cede y entrega sus conocimientos. Por eso quiero pedirte, a ti, socio de SETLA o no, que te animes a crecerte profesionalmente transmitiendo tu experiencia y saber hacer: esa es la razón de publicar hoy en RETLA.

https://doi.org/10.24129/j.retla.01202.fs1810015

FS () 2018 Sociedad Española de Traumatología Laboral. Publicado por Imaidea Interactiva en FONDOSCIENCE ${ }^{\circledR}$ (www.fondoscience.com) Este es un artículo Open Access bajo la licencia CC BY-NC-ND (www.creativecommons.org/licenses/by-nc-nd/4.0/). 
Nosotros no somos una revista de impacto, no nos encontrarás, por ahora, en los buscadores médicos, pero nuestro objetivo hoy no es ese, buscamos poder ofrecer al profesional sanitario laboral una herramienta que le pueda ayudar en su quehacer diario, en el manejo del paciente laboral y sus peculiaridades; por eso en esta revista caben todas las profesiones sanitarias y todas son bienvenidas.

Como editor de RETLA, solo me queda decirte que te invito a formar parte de los autores que harán historia en la patología laboral.

Un afectuoso saludo,

\section{Eduardo Sánchez Alepuz}

\section{Editor de RETLA}

